\title{
Microstructural and Compositional Gradients in the Filament-Matrix Region of Nb-Ti Wire Composites
}

\author{
Kenneth J. Faase and William H. Warnes \\ Department of Mechanical Engineering, Oregon State University \\ Corvallis, OR 97333 USA \\ Peter J. Lee and David C. Larbalestier \\ Applied Superconductivity Center, University of Wisconsin-Madison \\ Madison, WI 53706 USA
}

\begin{abstract}
Transverse cross-sections of $\mathrm{Nb}$ - $\mathrm{Ti}$ wire composites after final $\alpha$-Ti precipitation heat treatment $\left(10-480 \mathrm{hr} / 420^{\circ} \mathrm{C}\right)$ were examined and analyzed in the filament-matrix region with Scanning Electron Microscope-Backscatter Electron Imaging (SEM-BEI) and Electron Micro Probe Analysis (EMPA). SEMBEI micrographs were image analyzed to quantify the average effective $\alpha$-Ti precipitate diameter, $d^{*}$, and volume fraction of $\alpha$ $\mathrm{Ti}$ as a function of distance into the filament. $\mathrm{Cu}$ concentration profiles were found in the same regions by EMPA. The compositional results show trace amounts of $\mathrm{Cu}(>0.1 \mathrm{at} \%)$ interdiffused up to $50 \mu \mathrm{m}$ into the $\mathrm{Nb}$-Ti filaments. The interdiffused $\mathrm{Cu}$ at the interface increased $\alpha-\mathrm{Ti}$ nucleation and thus increased $\alpha$-Ti volume fractions by $50 \%$ relative to the nominally pure $\mathrm{Nh}$ - $\mathrm{Ti}$ at the center of the filament for short heat treatment times ( 30 hours of total heat treatment time).
\end{abstract}

\section{INTRODUCTION}

In recent years a direct relationship between the critical current density, $\mathrm{J}_{\mathrm{c}}$, and the microstructure of $\mathrm{Nb}-\mathrm{Ti}$ composites has been developed [1]-[3]. The current density of the $\mathrm{Nb}-\mathrm{Ti}$ has a strong, linear dependence on the volume percent of $\alpha-T i$ existing after the final heat treatment. The optimized microstructure of $\mathrm{Nb}-\mathrm{Ti}$ wires is developed by a series of heat treatments and wire drawing steps. The small $\alpha$-Ti precipitates (10-250nm), which exist after the final heat treatment, are then drawn into $1-5 \mathrm{~nm}$ thick ribbons by a final wire drawing strain of 4 to 5 . The $\alpha$-Ti ribbons act as the principal flux pinning sites for the fluxoid lattice.

We recently discovered [4] that the average size of the $\alpha$ $\mathrm{Ti}$ precipitates near the filament perimeter is smaller than the precipitates found at the center of the filament in some $\mathrm{Nb}-\mathrm{Ti}$ wires at their final heat treatment stage. This variable precipitate size is easily visible with a Scanning Electron Microscope in Backscatter Electron Imaging (SEM-BEI) mode. Due to the simplicity of sample preparation and the ability to choose specific viewing regions anywhere within the filament, the use of the SEM-BEI technique is here further investigated as a useful tool for precipitate quantification.

\section{EXPERIMENTAL Procedure}

The composites (Table I) in this study were two series of previously studied monofilamentary and multifilamentary Nb46.5wt\% Ti wires [4]-[6]. The samples all had excellent $J_{C}$ values $\left(>2700 \mathrm{~A} / \mathrm{mm}^{2}\right.$ at $5 \mathrm{~T}, 4.2 \mathrm{~K}$ ) and had been well studied microstructurally by transmission electron microscopy (TEM) [7].

Manuscript received October 17, 1994. This work was supported by the U. S. Department of Energy under Grants No. DOE-FG06-93ER40804 and No. DE-AC02-82ER-4007, Teledyne Wah Chang Alhany and the Oregon Metals Initiative.
TABLE I

COMPOSITE DETAILS

\begin{tabular}{|c|c|c|c|c|}
\hline \multicolumn{5}{|c|}{ COMPOSITE DETAILS } \\
\hline Composite II & Description & Heat Treatments & $J_{c}$ & Plot Symbol ${ }^{6}$ \\
\hline СВ2123 & Monofilament & $3 \times 10 \mathrm{hr} / 420^{\circ} \mathrm{C}$ & $2764^{\mathrm{a}}$ & - \\
\hline CB2133 & $\begin{array}{l}\text { No Nb wrap } \\
\text { Monofilament } \\
\text { No Nb wrap }\end{array}$ & $3 \mathrm{X} 40 \mathrm{hr} / 420^{\circ} \mathrm{C}$ & 3231 & $\Delta$ \\
\hline CB2163 & $\begin{array}{l}\text { Monofilament } \\
\text { No Nb wrap }\end{array}$ & $3 \times 120 \mathrm{hr} / 420^{\circ} \mathrm{C}$ & 3600 & $\mathbf{\square}$ \\
\hline CB2153 & $\begin{array}{l}\text { Monofilament } \\
\text { No Nb wrap }\end{array}$ & $3 \times 160 \mathrm{hr} / 420^{\circ} \mathrm{C}$ & 3616 & - \\
\hline $5263-3-C$ & $\begin{array}{l}\text { Multifilament } \\
\mathrm{Nb} \text { wrap }\end{array}$ & $3 \mathrm{X} 80 \mathrm{hr} / 420^{\circ} \mathrm{C}$ & 3196 & 0 \\
\hline UW6401C & $\begin{array}{l}\text { Multifilament } \\
\text { Nb wrap }\end{array}$ & $\begin{array}{l}2 \times 80 \mathrm{hr} / 420^{\circ} \mathrm{C}+ \\
1 \mathrm{X} 480 \mathrm{hr} / 420^{\circ} \mathrm{C}\end{array}$ & na & 口 \\
\hline
\end{tabular}

${ }^{\mathrm{a}} \mathrm{J}_{\mathrm{C}}$ measured at $4.2 \mathrm{~K}, 5 \mathrm{~T}$.

${ }^{b}$ Plot symbols are used in Fig. 3 and Fig. 4.

Transverse cross sections of the heat treated wires were mounted and polished in conductive bakelite for the electron microscopy. All samples were examined after their final $\alpha$ Ti precipitation heat treatment. SEM-BEI micrographs of the samples were taken at 10,000 times magnification using a JEOL $35 \mathrm{C}$ SEM operating at $20 \mathrm{kV}$ and an objective aperture of $240 \mu \mathrm{m}$. Compositional gradients of the samples were performed on a Cameca SX50 electron microprobe at an accelerating voltage of $15 \mathrm{kV}$ and $50 \mathrm{nA}$. The $\mathrm{Cu}_{\mathrm{K} \alpha 1}, \mathrm{Ti}_{\mathrm{K} \alpha 1}$, and $\mathrm{Nb}_{L \beta 1}$ peaks were analyzed for 30,10 and 10 seconds respectively. One Electron Micro Probe Analysis (EMPA) sample was etched $\left(\mathrm{H}_{2} \mathrm{O}: \mathrm{HNO}_{3}, 5: 1\right.$ by volume) for 60 seconds to check for any residual $\mathrm{Cu}$ on the $\mathrm{Nb}-\mathrm{Ti}$ due to polishing. The etched sample showed no significant change in the EMPA profile relative to its unetched state.

The $\alpha$-Ti precipitates in the SEM-BEI micrographs were quantitatively analyzed for both volume fraction and average effective precipitate diameter, $\mathrm{d}^{*}$, with image analysis. The micrographs were scanned into a Macintosh IIci with a video digitizer at a resolution of $\sim 16 \mathrm{~nm} / \mathrm{pixel}$ and 256 grey scales. The image analysis was performed on a modified version of NIH Image 1.49 [8].

Due to the large electron beam-specimen interaction volume at $20 \mathrm{kV}$, the $\alpha$-Ti precipitates in the SEM-BEI micrographs were diffuse in nature. To accommodate the diffuse precipitate boundaries, an image analysis algorithm was developed to locally transform the 256 grey scale map into linear-regression curve fits in order to statistically calculate local precipitate boundaries.

The algorithm scanned the 256 grey scale image for local minimums in image intensity (black: image intensity $=0$, white: image intensity $=255$ ) with a user defined kernel size. Each minimum point was marked and accepted or rejected by the user as a valid precipitate signal or as signal noise.

Each of the user accepted local minima then became the 
origin for a local polar coordinate system (Fig. 1). The algorithm radially scanned the grey scale intensity, $I$, as a function of sub-pixel, polar position, $(r, \theta)$. The scan went from the local minimum point, in one pixel length increments, to a local maximum on the grey scale surface. The grey scale value of $I(r, \theta)$ was linearly interpolated, at sub-pixel precision, as a function of position and grey scale intensity between $(r, \theta)$ and its nearest four neighboring pixels. The distance between the local minimum and maximum was then divided into twenty, equi-distant, subpixel precision lengths, $r_{n}$. A grey scale intensity array, $I\left(r_{n=1}\right.$ to $\left.20, \theta\right)$, was then calculated in the same manner as $\mathrm{I}(\mathbf{r}, \boldsymbol{\theta})$.

A fifth order linear regression fit, $I_{f i t}(r, \theta)$, was calculated for every intensity array, $I\left(r_{n=1}\right.$ to 20, $\left.\theta\right)$. The maximum in the gradient of $I_{f i t}(r, \theta)$ was then taken as the effective radius, $r^{\dagger}$, of the precipitate at the angle $\theta$. The angle $\theta$ was incremented by a user defined $\mathrm{d} \theta$, and a sub-area, $\mathrm{dA}$, was calculated as $(1 / 2)\left(\mathrm{r}^{\dagger}\right)^{2} \mathrm{~d} \theta$. The total area of the precipitate was then found by calculating $\mathrm{r}^{\dagger}(\theta)$ and $\mathrm{dA}(\theta)$ for all $\theta$ from 0 to $2 \pi$ and summing the sub-areas.
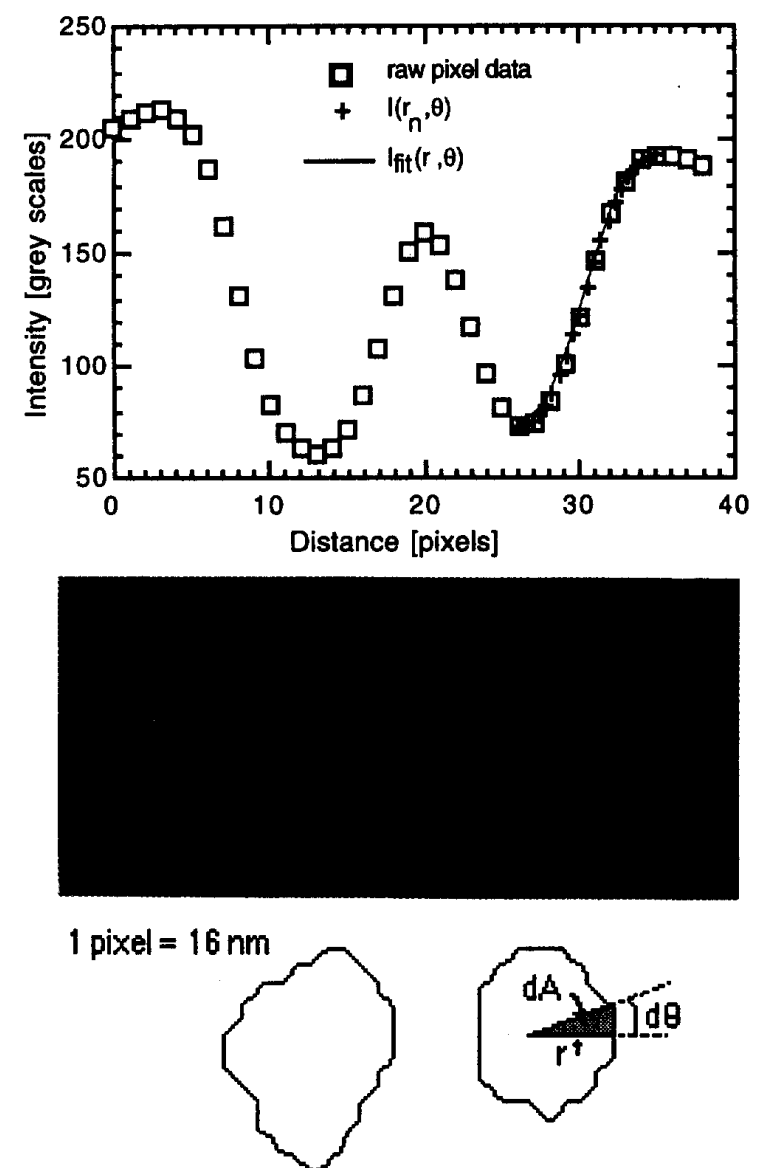

Fig. 1. The top plot is an intensity profile of the raw pixel data from the white line crossing the grey scale image of two precipitates in the middle figure. Also included in the plot is a radial array $I\left(r_{n=1}\right.$ to $\left.20, \theta\right)$ and a regression fit $I_{f i t}(r, \theta)$ represented by the triple-black/white line on the grey scale image. The bottom figure shows the perimeter of the two precipitates as calculated by the algorithm, as well as a schematic of $r^{\dagger}, d \theta$ and $d A$.
Finally, the algorithm produced a binary image of the calculated perimeters of the precipitates. The binary image was overlaid upon the original 256 grey scale map to check the integrity of the calculation.

From each sample, four $5 \mu \mathrm{m} \times 5 \mu \mathrm{m}$ areas were image analyzed in the center of the filament. To measure the microstructural gradients, two to four $2.5 \mu \mathrm{m} \mathrm{X} 2.5 \mu \mathrm{m}$ areas were analyzed in $\sim 2 \mu \mathrm{m}$ spacings from the perimeter towards the center of the filament. EMPA traces were taken in the same regions to complement the microstructural measurements.

\section{RESUlts}

A comparison of the microstructures at the center and the edge of a filament is shown in Fig. 2. The micrographs confirm the average $\alpha$-Ti precipitate diameter is smaller at the filament perimeter than at the filament center as suggested in [4]. Although an apparent change in $d^{*}$ exists, no qualitative change in volume fraction of $\alpha$-Ti is noticeable between the two regions.
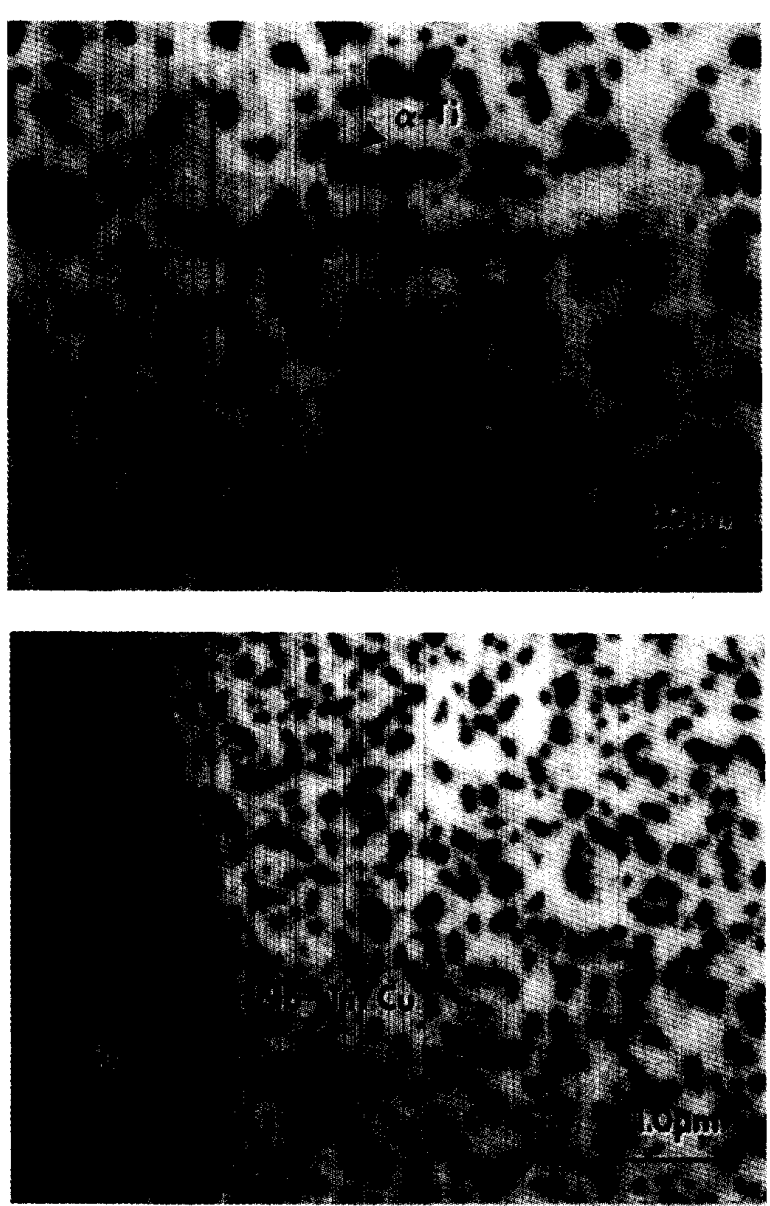

Fig 2. SEM-BEI micrographs of the CB2163 sample after final precipitation heat treatment. The center and perimeter regions of the filament are shown in the top and bottom micrographs respectively. Intermetallic compound can be scen at the filament-matrix perimeter. 
Quantitative microstructural profiles of the two regions are shown in Fig. 3. Fig. 3a depicts $\mathrm{d}^{*}$ as a function of distance from the filament-matrix interface for the six samples. The $\mathrm{d}^{*}$ profiles are a function of total heat treatment time. The UW6401C sample, with a total heat treatment time of $640 \mathrm{hr} / 420^{\circ} \mathrm{C}$, has an $\sim 25 \%$ reduction in $\mathrm{d}^{*}$ from the center of the filament to the filament perimeter. Both the CB2123 and CB2133 samples, with total heat treatment times of 30 and 120 hours at $420^{\circ} \mathrm{C}$, respectively, have flat $\mathrm{d}^{*}$ profiles.

The volume fraction of $\alpha$-Ti profiles, Fig. 3b, are also dependent on the total heat treatment time of the sample. In this case, the volume fraction profiles have significant changes, from the filament perimeter to center, only in the samples with low total heat treatment times. CB2123 and CB2133 have $\alpha$-Ti volume fraction increases of $\sim 50 \%$ from the filament perimeter relative to the filament center, while UW6401C has a flat volume fraction profile.

EMPA traces of the filament-matrix regions are shown in Fig. 4. In the samples with no Nb wrap, CB2123 and $\mathrm{CB} 2153$, the profiles are again a function of the total heat treatment time of the sample. CB2123, with 30 hours of total heat treatment time, has $\mathrm{Cu}$ traces $(>0.1$ at\% $)$ up to 20
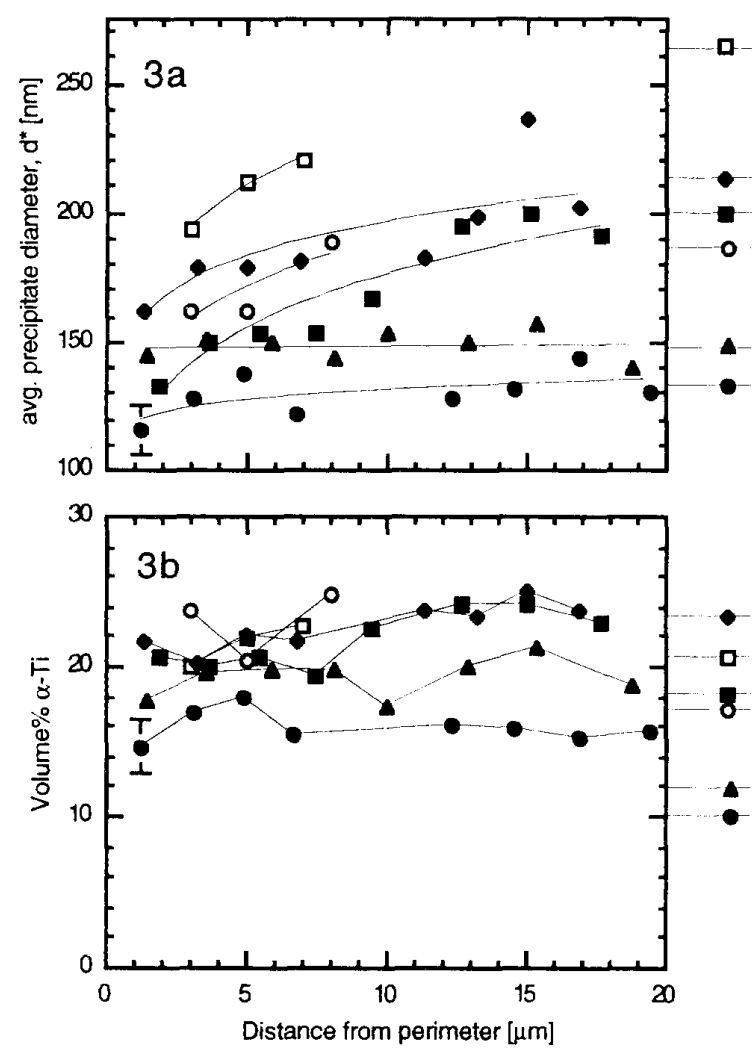

Fig. 3. Microstructural profiles, $d^{*}$ (3a) and volume fraction of $\alpha$-Ti (3b), of the six samples listed and identified in Table 1 . The lines and symbols at the right hand side of the graphs represent the measurement of the microstructure at the center of the filament for each sample. Each data point is the average of several measurements, with the error bar in each graph representing a typical standard deviation of the average microns into the $\mathrm{Nb}-\mathrm{Ti}$ filament, while CB2153, with 480 hours of total heat treatment time, has $\mathrm{Cu}$ traces up to 50 microns into the filament. In the two samples with $\mathrm{Nb}$ wraps, 5263-3-C and UW6401C, the Cu profiles are similar to each other (as well as similar to the trace for CB2153) yet the total heat treatment times are different by more than a factor of two.

The volume fraction of $\alpha$-Ti at the center and the perimeter of the filament is plotted against total heat treatment time in Fig. 5. The figure shows that the volume fraction of $\alpha-\mathrm{Ti}$ is higher in the perimeter region than in the center region of the $\mathrm{Nb}-\mathrm{Ti}$ filament for total heat treatment times of less than $\sim 200$ hours. After 200 hours of total heat treatment time, both the center and perimeter regions begin to saturate with $-20-25$ volume percent of $\alpha$-Ti precipitate.

The number density of $\alpha$-Ti precipitates, $\rho$, of each composite is estimated as

$$
\rho=\left[\frac{4 v \alpha-T i}{\pi d^{*}}\right]
$$

where $v_{\alpha-T i}$ is the volume fraction of $\alpha$-Ti. The estimated number densities are listed in Table II. In all of the samples, except CB2133, the number density of $\alpha$-Ti precipitate is higher at the filament perimeter than at the center region.

\section{DISCUSSION}

The newly developed SEM-BEI microstructural quantification technique has been applied to a simple thermal study. An advantage of this technique relative to TEM examination is the ability to freely choose a region of interest, where the TEM is limited by the available thin area of the sample. This has provided new insights on the microstructural-processing relationship in these composites which has not been possible with the TEM [9].

The presence of $\mathrm{Cu}$ in the $\mathrm{Nb}-\mathrm{Ti}$, which increases the nucleation rate of the $\alpha-\mathrm{Ti}$ precipitates, may offer modest benefits to the performance of the Nb-Ti composites in two possible ways. First, the volume fraction of $\alpha$-Ti in the

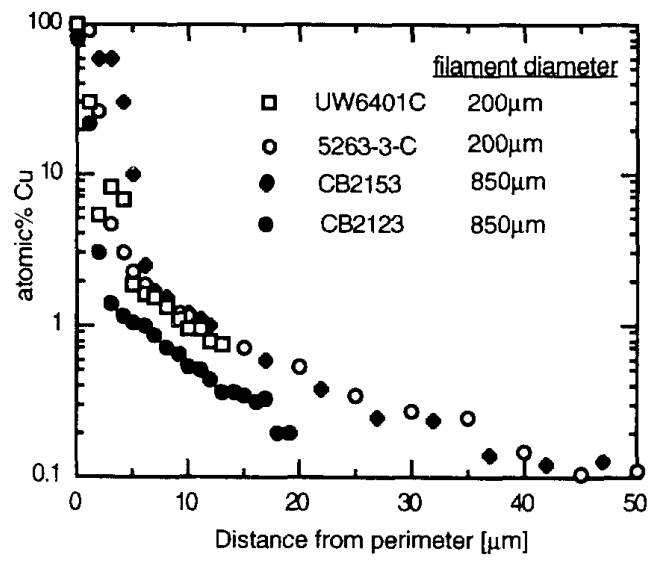

Fig. 4. EMPA Cu profiles. Both UW6401C and CB2153 show intermetallic peaks within $5 \mu \mathrm{m}$ of the filament-matrix interface. The detection limit for $\mathrm{Cu}$ is $\sim 0.1$ at $\% \mathrm{Cu}$. 
TABLE II

NUMBER DENSITY OF $\alpha$-Ti PRECIPITATES

\begin{tabular}{lllll}
\hline & $\begin{array}{c}\text { Total Heat } \\
\text { Treatment }\end{array}$ & $\begin{array}{l}\rho, \text { Filament } \\
\text { Perimeter } \\
\text { Composite ID } \\
\text { Time[hr] }\end{array}$ & $\begin{array}{l}\text { p, Filament } \\
\text { Center } \\
{\left[\text { [\#/4m }{ }^{2}\right]}\end{array}$ & $\begin{array}{l}\text { Percent } \\
\text { Difference }\end{array}$ \\
\hline CB2123 & 30 & $15.2 \pm 3.6$ & $7.3 \pm 2.8$ & 52 \\
CB2133 & 120 & $11.3 \pm 1.5$ & $6.9 \pm 3.8$ & (ns) \\
$5263-3-C$ & 240 & $11.5 \pm 1.2$ & $7.4 \pm 2.6$ & 36 \\
CB2163 & 360 & $15.7 \pm 4.4$ & $5.6 \pm 1.7$ & 64 \\
CB2153 & 480 & $12.4 \pm 3.1$ & $6.6 \pm 1.8$ & 47 \\
UW6401C & 640 & $7.52 \pm 2.46$ & $3.68 \pm 1.36$ & 51 \\
\hline
\end{tabular}

(ns) This result was statistically non-significant.

regions containing $\mathrm{Cu}$ is higher than the regions containing no $\mathrm{Cu}$ for total heat treatment times of 200 hours and less. The additional precipitate should provide additional pinning sites for the fluxon lattice, thus increasing $J_{c}$. Second, for total heat treatment times of $\mathbf{2 0 0}$ hours of more, the decrease in $\mathrm{d}^{*}$, due to the presence of $\mathrm{Cu}$, should reduce the amount of final strain needed to reach peak $\mathrm{J}_{\mathrm{c}}$.

On the other hand, $\mathrm{Cu}$ may be detrimental to the overall superconducting properties of $\mathrm{Nb}-\mathrm{Ti}$ composites. Reference [10] studied the structure and superconducting properties of prepared Ti60wt\% $\mathrm{Nb}$ alloys containing trace amounts of $\mathrm{Cu}$. Although they confirm increased nucleation of the $\alpha-\mathrm{Ti}$ precipitate with trace amounts of $\mathrm{Cu}$, they also find that the alloys with $\mathrm{Cu}$ exhibit reduced $\mathrm{T}_{\mathrm{c}}$. Additionally, reduced superconducting electron energy gaps have been found in $\mathrm{Nb}$ - $\mathrm{Ti}$ wire composites containing up to $3 \mathrm{wt} \% \mathrm{Cu}[11]$.

Whether beneficial or detrimental, the " $\mathrm{Cu}$-poisoned" zone will play a larger role as the development of conventionally processed wire composites strives for smaller $\mathrm{Nb}$-Ti filament diameters. The $50 \mu \mathrm{m}$ thick layer of $\mathrm{Cu}$ contamination $(>0.1 \mathrm{at} \%)$ in the CB2153 and 5263-3-C samples represent $\sim 22 \%$ and $\sim 75 \%$ of the cross sectional area of the filaments in these conductors, which have final filament diameters of 85 and $20 \mu \mathrm{m}$, respectively. Wire composites with final filament diameters of $\sim 10 \mu \mathrm{m}$ or less, processed in a similar manner, should have their entire cross sectional area contaminated with 0.1 at $\% \mathrm{Cu}$ or greater.

The extent of the $\mathrm{Cu}$ interdiffusion through the $\mathrm{Nb}$ wrap was an unexpected result of this study. Qualitatively, 52633-C had no signs of the "Cu-poisoned" zone and it was thought to take over 400 hours for the $\mathrm{Cu}$ to cross the $\mathrm{Nb}$ barrier in the sample [4]. Yet the sample had $\mathrm{Cu}$ contamination up to $50 \mu \mathrm{m}$ into the $\mathrm{Nb}-\mathrm{Ti}$ filament which produced a higher number density of $\alpha$-Ti precipitates at the perimeter than the center of the filament.

It appears that $\mathrm{Cu}$ does not see a substantial barrier to interdiffusion through the $\mathrm{Nb}$ wrap until concentrations reach a level high enough to form $\mathrm{Cu}-\mathrm{Ti}$ intermetallics $(>10$ at $\% \mathrm{Cu})$. This would suggest that the $\mathrm{Cu}$ is readily diffusing along the grain boundaries of the $\mathrm{Nb}$ wrap and $\mathrm{Nb}$ Ti filament, in these heavily deformed composites, until the $\mathrm{Cu}-\mathrm{Ti}$ intermetallic compound has formed. The intermetallic layer then acts as a sink for additional interdiffused $\mathrm{Cu}$, thus leaving the profile of the trace amounts of $\mathrm{Cu}$ in $\mathrm{Nb}-\mathrm{Ti}$ effectively stationary.

Finally, although the SEM-BEI technique has proven to be quite useful in this study and in quantifying the microstructure in Nb-Ti Artificial Pinning Center (APC) materials [12], it cannot fully replace the TEM

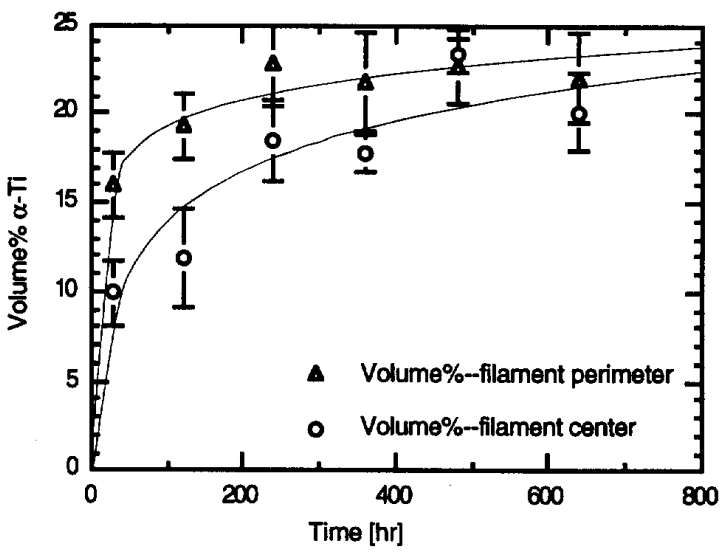

Fig. 5. Volume fraction of $\alpha$-Ti versus total heat treatment time. Each perimeter point and error bar represents the average and standard deviation of the volume fraction measurements in the first $20 \mu \mathrm{m}$ of the filament-matrix region as shown in Fig. 3. Each center point is simply the average and standard deviation of four measurements made at the center of the filament.

microstructural quantification technique. The SEM-BEI quantification technique is ultimately limited by the electron beam-specimen interaction volume to a resolution of $\sim 10 \mathrm{~nm}$. Ideally, this technique should be able to quantify microstructures with an average, gaussian-distributed particle diameter of $\sim 25 \mathrm{~nm}$ and still have volume (area) fraction measurements accurate within 5\% of the TEM. In practice, this average precipitate diameter limit has been found to be more on the order of $\sim 50 \mathrm{~nm}$. This excludes the SEM-BEI technique from quantifying the microstructure of these $\mathrm{Nb}-\mathrm{Ti}$ composites in both their earliest and final microstructural-processing stages, where the $\alpha$-Ti precipitate is in the form of grain boundary films or ribbons.

\section{ACKNOWLEDGMENT}

We would like to thank Rick Noll for his help on the SEM and Roger Nielsen for his assistance on the EMPA.

\section{REFERENCES}

[1] P. J. Lee, J. C. McKinnell, and D. C. Larbalestier, Adv. Cryo. Eng., vol. 36, pp. 287-294, 1990.

[2] P. J. Lee, J. C. McKinnell, and D. C. Larbalestier, Adv. Cryo. Eng., vol. 40A, pp. 725-732, 1994

[3] O.V. Chernyi, et al., Superconducting Science \& Tech., vol. 4, pp. 318 323, 1991.

[4] K. J. Faase, P. J. Lee, J. C. McKinnell, and D. C. Larbalestier, Adv. Cryo. Eng., vol. 38, pp. 723-730, 1992.

[5] Li Chegren and D. C. Larbalestier, Cryogenics, vol. 27, pp. 171-177, 1987.

[6] Y. E. High, P. J. Lee, J. C. McKinnell, and D. C. Larbalestier, Adv. Cryo. Eng ,, vol. 38, pp. 647-652, 1992.

[7] P. J. Lee, "Superconducting Materials: Fabrication and Process Variables", SSCL/ndustry Technology Transfer, June 1991.

[8] NIH Image is a public domain software package available via the INTERNET @ ftp.soils.umn.edu.

[9] K. J. Faase, M.S. thesis, University of Wisconsin-Madison, 1992, (available from University Microfilms, Ann Arbor, Michigan).

[10] V. A. Vozilkin, T. L. Trenogina, S. B. Volkova and V. P. Korzhov, Fiz. metal. metalloved., vol. 6, pp. 183-187, 1991.

[11] J. Moreland, J. W. Ekin, and L. F. Goodrich, IEEE Trans. Mag., vol. 23, pp. 1101, 1985.

[12] L. D. Cooley, Ph.D. thesis, University of Wisconsin-Madison, 1993, (available from University Microfilms, Ann Aror, Michigan). 